\title{
A INTERPRETAÇÃO NO DIREITO AGRÁRIO
}

\author{
Fábio Maria De-Mattia \\ Professor Titular de Direito Agrário da Faculdade de Direito da USP
}

Resumo:

Uma vez reconhecida a existência da especialidade do Direito Agrário, o autor visa estudo das interpretações aplicadas a este novo ramo do Direito, além de outros aspectos pertinentes ao tema, como o Direito Agrário Positivo brasileiro.

Abstract:

Once more admited the existence in the speciality of the Agrarian Law, like a new ramification of the Civil Law, the author speaks about interpretations puts in practice of this recently branch of the Law, included another aspects to the theme: the brazilian Agrarian Law Positive.

Unitermos: interpretação usual e analógica, ratio-legis.

\section{Sumário:}

Introdução

1 A interpretação usual como fonte de Direito.

2 A interpretação analógica e os princípios gerais de Direito Agrário.

3 - A ratio-legis e a interpretação evolutiva.

4 - Os limites e conteúdo da ratio-legis.

5 - Caracteres da ratio-legis:

a) normalidade dos acontecimentos;

b) diligência do bom pai de família;

c) o princípio da confiança.

6 - Outros aspectos pertinentes ao tema e o Direito Agrário Positivo brasileiro.

Introdução

Com o reconhecimento da existência da especialidade do Direito Agrário impõe-se o estudo da interpretação aplicada a este ramo do Direito. 
Este capítulo sob o ponto de vista sistemático deve ser desenvolvido após o estudo das noções de institutos, princípios gerais, e especialidade do Direito Agrário, porém, reconhecida a centralidade da empresa, didaticamente, melhor será inseri-lo após estudar a empresa e o estabelecimento agrários.

Paolo Vitucci noticia que os próprios estudiosos da teoria geral do Direito asseveram que as diferenças entre os vários setores da experiência jurídica não são privadas de relevância também em sede de interpretação da lei; as sondagens e aprofundamentos circunscritos a cada disciplina devem ser considerados profícuos. ${ }^{1}$

Juan José Sanz Jarque, ilustre representante da escola agrarista espanhola, ao estudar as formas de expressão do Direito Agrário, concorda apresentarem elas efetivamente peculiaridades quanto à sua hierarquia e interpretação, ainda que derivadas e dependentes do tronco principal representado pelo Direito Privado.

Sustenta, além disso e com razão, que o direito comum ordinário, derivado do Código Civil, tem valor de fonte principal, vigente sempre que a matéria não é regulada pelas leis agrárias e pelos usos agrícolas. ${ }^{2}$

Giovanni Galloni, autor de monografia sobre a interpretação das leis, estuda a matéria tendo em vista o Direito Agrário e o faz sob vários ângulos: 1. A interpretação usual como fonte do direito; 2. A interpretação analógica e os princípios gerais do Direito Agrário; 3. A ratio-legis e a interpretação evolutiva; 4. Limites e o conteúdo da ratio-legis; 5 . Caracteres da ratio-legis: a. normalidade dos acontecimentos (id quod plerumque accidit); 6. b. Diligência do bonus pater familias; 7. c. o princípio da confiança (bona fides). ${ }^{3}$

Passemos, pois, à avaliação destas perspectivas.

1. Vitucci, Paolo, Sull'applicazione analogica delle leggi agrarie, in Rivista di Diritto Agrario, Milano, v. 62, n. 1, 1983, p. 5.

2. Sanz Jarque, Juan José, Actualidad y fuentes del moderno Derecho Agrario, Milano, in Rivista di Diritto Agrario, v. 57, n. 1, 1978, p. 20 e 21.

3. Galloni, Giovanni, Lezioni sul diritto dell'impresa agraria, $2^{\mathrm{a}}$ ed., Milano, Liguori Editrice, 1984, p. 122. 
1 A interpretação usual como fonte do Direito.

A interpretação usual consiste na aplicação da norma na atividade de relação comum, quotidiana no interior do corpo social. O sujeito, na vida concreta de relação, entende intuitivamente o dever ser do comportamento sem se aperceber se a fonte do preceito jurídico resida numa norma escrita ou em norma não-escrita. ${ }^{4}$

A interpretação tende a ser evolutiva, respeitando as mutações em curso no corpo social. Esta noção se expressa, no campo do Direito Agrário, ao se afirmar que, na agricultura, o direito nasce da natureza dos fatos e das coisas, ou seja, que as exigências de uma realidade em evolução criam problemas sempre novos que o agricultor deve ter presente e que o leva a adaptar seu comportamento. Como negar a juridicidade de tal comportamento? Ele é secundum ius ou típico desde que qualquer outro agricultor médio ter-se-ia conduzido do mesmo modo.

Conclui Giovanni Galloni que o juiz, então, deverá reconhecer, ao lado das normas escritas, também, a existência de normas não-escritas, quer as acolha sob o perfil de costume praeter legem quer sob o perfil de uma extensão ou restrição do significado das normas escritas. ${ }^{5}$

2 - A interpretação analógica e os princípios do Direito Agrário.

Giovanni Galloni ressalta a importância dos princípios gerais na interpretação da lei, quer sejam princípios gerais de uma matéria quer sejam os princípios gerais do ordenamento jurídico.

Define os princípios gerais de uma matéria como princípios nãoescritos que penetram na ratio de qualquer norma escrita inspirando-lhes o conteúdo. No processo interpretativo é possível através do recurso à analogia legis encontrar em norma análoga a disciplina de um suporte fático não-regulada expressamente.

É comum, ademais, afirmar-se que na interpretação analógica aplicase ao caso concreto não regulado uma norma escrita que disciplina suporte fático semelhante. Contudo, na realidade, o mecanismo que atua parece ser aquele através do qual aplica-se ao caso concreto uma norma não-escrita, cujo conteúdo se extrai

4. Id., ibid., p. 123.

5. Id., ibid., p. 122. 
dos princípios gerais do ordenamento jurídico ou de princípios reguladores do assunto. $^{6}$

Aponta o autor, por outro lado, que se costuma identificar para o Direito Agrário alguns de seus princípios gerais que orientam a interpretação analógica e auxiliam explicar a ratio das normas agrárias e com fundamento em tais princípios são elaboradas as normas legais sobre Direito Agrário e agricultura.

Neste sentido Giovanni Galloni, autor de obras fundamentais em nossa disciplina e que, com profundidade, estudou a questão da interpretação no Direito Agrário, parece admitir como válida a existência dos já referidos princípios gerais do Direito Agrário, tanto que enumera aqueles mesmos enunciados por Carlo Frassoldati que são: a) adequado cultivo da terra; b) fixação da extensão da empresa, leia-se propriedade agrícola, de acordo com os interesses da produção; c) nãocindibilidade dos resultados gerais da produção agrária; d) colaboração das partes na execução dos contratos agrários; e) a colaboração entre as propriedades, melhor dizendo empresas agrárias. ${ }^{7}$

Deduz-se que nem sempre trata-se de princípios jurídicos.

Os termos dos itens $b$ e $c$ se justificam em consequiência do deslocamento do instituto da propriedade agrária para o instituto empresa agrária. ${ }^{8}$

Quanto à referência aos princípios gerais de Direito Agrário, conforme já afirmado anteriormente, devemos externar nossa posição de discordância quanto à existência real de tais princípios, seguindo a tendência majoritária da doutrina agrarista contemporânea.

A boa produção pode ser considerada como o critério fundamental e resumido de todo o ordenamento agrário produtivo.

Se considerarmos o Direito Agrário como direito da empresa agrária, boa produção é o fim último para o qual se dirige toda a atividade produtiva.

Daí o Direito Agrário poder ser interpretado e ordenado tendo como base o critério do cultivo adequado.

Em consequiência, a obrigação de boa produção é imposta ao empresário - proprietário sob sanção de desapropriação por abandono de exploração
6. Id., ibid., p. 123.
7. Id., ibid., p. 123 e 124 .
8. Id., ibid., p. 124. 
da terra, também se esta estiver sendo insuficientemente aproveitada ou se for excessivamente cultivada desrespeitando padrões previamente fixados. ${ }^{9}$

O princípio do respeito às normas da boa técnica agrária, por exemplo, quando se tratar de execução de contratos agrários, surge as normas que determinam que o arrendatário ou parceiro-outorgado deva cultivar respeitando os padrões aplicáveis, eventualmente, observando a destinação agrária empreendida pelo concedente e até prescrevendo que o pequeno arrendatário ou parceiro outorgado possa ser assistido técnica e financeiramente pelo concedente. ${ }^{10}$

Quanto à dimensão da propriedade agrícola, temos a ressaltar os aspectos do limite mínimo da Unidade Produtiva, a disciplina criativa para a recomposição fundiária, critérios para a redução de dimensões de propriedades muito extensas. $^{11}$

A não-cindibilidade dos resultados obtidos no período de um ano leva à consideração do princípio da continuação da produção agrária, daí a preocupação legislativa com a fixação de prazo mínimo na duração dos contratos agrários.

\section{A ratio-legis e a interpretação evolutiva}

Giovanni Galloni ensina que a interpretação de toda lei e, também, das leis agrárias, consiste fundamentalmente na pesquisa da ratio-legis, que não insiste em indagar a vontade do legislador, mas sim o significado, isto é, o interesse ou escopo prático tutelado pela norma.

Esta pesquisa permite especificar o interesse típico do qual participam cada ato e os comportamentos diversos realizados conforme a lei.

A ratio-legis indica a atitude da norma escrita ao adaptar-se no seu verdadeiro significado, no seu alcance real, à natureza dos fatos e das coisas. ${ }^{12}$

Giovanni Galloni explica como a investigação da ratio de uma norma não é a procura da vontade psicológica do legislador (ou seja, o que o legislador quis dizer quando formulou a norma), mas sim a indagação do significado da norma no

9. Id., ibid., p. 124.

10. Id., ibid., p. 124, que exemplifica com os arts. 1.615 e 1.652 do Código Civil Italiano e com o art. 16 da Lei n. 203, de 13 de maio de 1982.

11. O instituto - unidade produtiva - é previsto na Lei italiana n. 203, de 1982.

12. Id., ibid., p. 125. 
contexto do ordenamento jurídico e da sociedade em que vive (isto é, o que a norma deseja significar hoje, propondo-se à tutela do interesse típico examinado). A interpretação não pode ser mais uma avaliação subjetiva do intérprete, devendo esse estar, sempre, ligado à objetividade da norma, isto é, tal como a norma mostra-se evidente ao término de seu processo evolutivo no interior do ordenamento. ${ }^{13}$

Em outros termos, não é o intérprete quem modifica ou faz com que a norma progrida, mas é a norma que progride no contexto institucional, tendo em vista a própria modificação das relações, evolução esta que o intérprete não pode não ter presente. Daí, Giovanni Galloni concluir, que a função jurisprudencial, portanto, permanece, sempre, a de averiguação do direito existente no ordenamento e nunca a produção de novo direito. ${ }^{14}$

\section{4 - Os limites e conteúdo da ratio-legis}

Giovanni Galloni preleciona que adentrando no exame dos caracteres da tipicidade e da ratio da lei, com particular atenção às leis agrárias, impõe-se iniciar ressaltando que um limite fundamental e inderrogável da juridicidade localiza-se no critério da possibilidade. Não cabe, no âmbito do ordenamento jurídico e social, tudo aquilo que tem atuação impossível.

Acentua que o princípio ad impossibilia nemo tenetur ultrapassa o campo específico das obrigações e assume um alcance mais geral.

O direito está sempre conforme a natureza das coisas e do homem, participando de racionalidade intrínseca. $\mathrm{O}$ dever ser jurídico apresenta-se, portanto, sempre como um esquema de conduta possível de se realizar. ${ }^{15}$

$\mathrm{O}$ conceito de possibilidade, ensina o mestre italiano, define, pois, os limites da ratio-legis, no sentido que estabelece os limites além dos quais a norma que seja impossível de se realizar perderá os caracteres de juridicidade. Todavia, o conteúdo concreto da ratio pode ser indagado apenas em relação ao escopo prático assumido pela norma, ou seja, a ratio da norma e o significado causal devem ser interpretados em função do fim próprio que as normas alcançam dentro do ordenamento.

13 Id., ibid., p. 126.

14. Id., ibid., p. 126.

15. Id., ibid., p. 126. 
Arrematando, Giovanni Galloni afirma que é por isso que as normas que estão em conexão entre si para a disciplina de um instituto devem ser interpretadas umas por meio das outras e todas em relação ao interesse prático para cuja tutela são dirigidas. ${ }^{16}$

Relacionando estas noções gerais com o Direito Agrário, Giovanni Galloni assevera, como se sustenta, que o Direito Agrário é sobretudo o direito que disciplina a empresa agrária, com o que o ponto de referência da ratio para a interpretação das normas agrárias não pode ser senão o ordenamento da empresa. Assim, o interesse da empresa, ou seja, a produção agrícola é, em outras palavras, a chave da interpretação do Direito Agrário. A norma agrária, portanto, é sempre instrumental com respeito aos fins da empresa agrária e, por consequiência, deve ser interpretada em função destes fins. ${ }^{17}$

Giovanni Galloni ensina que a estrutura das diretrizes da interpretação no Direito Agrário é feita, portanto, a partir do momento em que se estabelece que a ratio da norma pode ser definida, em linhas gerais, através de três critérios interpretativos fundamentais: o princípio da normalidade dos acontecimentos (o quod plerumque accidit); o princípio da obrigatoriedade da conduta (diligência do bonus pater familias) e o princípio da confiança (bona fides).

Em conclusão, Giovanni Galloni estabelece que para a interpretação do Direito Agrário estes critérios são usados em função da empresa agrária e de seus fins produtivos. ${ }^{18}$

\section{5 - Caracteres da ratio-legis}

a) normalidade dos acontecimentos (quod plerumque accidit)

O quod plerumque accidit responde ao princípio, ínsito em toda norma, do interesse prevalecente e, em caso de conflito de interesses, do sacrifício do interesse atípico, isolado, anômalo, com relação àquele que melhor responde aos fins da organização social.
16. Id., ibid., p. 126 e 127.
17. Id., ibid., p. 126.
18. Id., ibid., p. 127. 
Isto não quer dizer que o interesse prevalecente será determinado com base em critérios puramente quantitativos e de freqüência, pois, se assim fosse, dever-se-ia igualmente dar o batismo de juridicidade ao comportamento que respondesse a interesses outros, fora de qualquer tutela de valores. $O$ interesse prevalecente tutelado é sempre aquele que, além de responder aos fins individuais, responde, também, aos fins gerais da conservação e do crescimento do ordenamento. $^{19}$

Em muitos casos, porém, frente a um conflito entre dois tipos de interesses, qualquer um dos quais seja por si merecedor de tutela, o ordenamento atribui ao intérprete tarefa de avaliar, frente a situação concreta e com base no princípio do id quod plerumque accidit, qual seja o interesse prevalecente. ${ }^{20}$

Para exemplificar pode-se ter presente um standard jurídico, qual seja a noção de exercício normal da agricultura. Ela será o divisor para a fixação dos limites entre empresa agrícola e a empresa comercial.

Fixados tais limites, o próximo passo é o da determinação da disciplina a que devem ser submetidas certas atividades (de transformação e de alienação dos produtos agrícolas). ${ }^{21}$

Giovanni Galloni formula o parâmetro necessário ao assentar que é evidente que em tal caso o intérprete se deve referir, para a avaliação da normalidade, a um critério objetivo, e que este não pode ser fornecido apenas pela avaliação da freqüência em sentido estatístico dos comportamentos (aquilo que a maioria dos agricultores faz ou tem feito ordinariamente), mas sim como instrumento daquilo que o agricultor normalmente faz para responder aos princípios da boa produção conforme a evolução da técnica agrícola e da ciência econômica. ${ }^{22}$

Subsídios para uma avaliação prática do standard jurídico - exercício normal da agricultura - encontramos em Mario Ghidini, que se baseia na atuação de uma determinada categoria de agricultura. ${ }^{23}$

19. Id., ibid., p. 127.

20. Id., ibid., p. 127.

21. Id., ibid., p. 127, informa que o Código Civil italiano, no art. 2.135 pede ao intérprete que este estabeleça quando estas atividades "se enquadrarão no exercício normal da agricultura."

22. Id., ibid., p. 127.

23. Ghidini, Mario, Lineamenti del' Diritto dell'impresa, $2^{\mathrm{a}}$ ed. rev. e atual., Milano, Dott. A Giuffrè Editore, 1978, p. 36-8. 
b) diligência do bom pai de família

Giovanni Galloni aponta tratar-se, na realidade, não da diligência em abstrato do homem médio, conforme uma média, por assim dizer, aritmética de comportamento, mas da diligência exigida para alcançar os fins lícitos e possíveis, colocados pelo ordenamento.

Acentua que cada ato produtivo de efeitos jurídicos deve ser avaliado pelo intérprete para o exame de sua correlação com o fim a que é dirigido, desde que este fim seja lícito e possível.

Quando tal ato for expresso no âmbito do exercício de um poder jurídico, responde pois a um critério de discricionalidade, pedindo-se ao intérprete que avalie caso a caso se aquele não exorbitou do próprio fim. ${ }^{24}$

Esta avaliação não pode se verificar senão através do critério da diligência do bom pai de família, um critério elástico e que se adequa à evolução da realidade. Giovanni Galloni ressalta que se deve avaliar como se teria comportado, qual escolha teria feito (coincidente ou não com aquela efetuada) o homem dotado de diligência normal em idêntica situação. ${ }^{25}$

Para o intérprete, assim, será sempre exigida a pesquisa da diligência do bom pai de família na avaliação do comportamento de quem administra ou tem a responsabilidade da direção da empresa.

Exemplo é aquele oferecido pelo concessionário no uso de propriedade agrária, que é obrigado a atuar de conformidade com sua destinação agrária, segundo a diligência do bom pai de família, fornecendo ao serviço do empreendimento os instrumentos para sua gestão e observando as regras técnicas de boa empreitada. ${ }^{26}$

Em todos os suportes fáticos examinados, pondera Giovanni Galloni, $o$ critério de diligência do bom pai de família é sempre aplicado, pelo intérprete, no caso concreto à luz do interesse objetivo da empresa agrícola, isto é, de um interesse que vem avaliado em relação ao progresso da técnica e à observância das normas de boa técnica ou da ciência econômica. ${ }^{27}$

24. Galloni, Giovanni, ob. cit., p. 128.

25. Id., ibid., p. 128.

26. Id., ibid., p. 128.

27. Id., ibid., p. 128 e 129. 
c) O princípio da confiança (bona fides)

A confiança reside na base de cada relação jurídica, seja como confiança a uma aparência jurídica, seja como expectativa do comportamento alheio.

Todos os sujeitos, com efeito, devem poder contar com isso: que outros sujeitos, os quais se relacionam com eles, comportar-se-ão conforme exige a boa-fé no adimplemento das obrigações impostas por lei. Se não existisse esta presunção, a vida da relação tornar-se-ia impossível. ${ }^{28}$

$\mathrm{O}$ elemento fiduciário adquire um relevo autônomo apenas quando é atribuído ao intérprete a tarefa de determinar no caso concreto a existência da confiança; isto ocorre, justamente, quando existem dois grupos de interesses em conflito, ambos em abstrato merecedores de tutela. ${ }^{29}$

Trata-se, em geral, de casos onde surge do contrato ou do fato um dever específico ou qualificado de cooperação entre as partes e este dever não é disciplinado como tal por cláusulas contratuais ou pela lei, mas se origina como dever jurídico conforme o princípio fundamental da boa-fé.$^{30}$

A ratio não pode, então, ser procurada na vontade das partes como aparece nas declarações negociais, mas deve ser procurada nos princípios que regulam o ordenamento privado e nos fins em que esse se inspira.

Este problema interpretativo se coloca, no campo do Direito Agrário, de maneira específica com respeito aos contratos agrários que são constitutivos da empresa agrícola. ${ }^{31}$

Giovanni Galloni exemplifica, asseverando que os problemas concernentes ao ordenamento interno da empresa, vistos em relação a fatos sobrevindos que alterem o equilíbrio originário entre as partes, frequientemente não podem ser solucionados reportando-se apenas às cláusulas contratuais, mas devem, ao invés, ser resolvidos com recurso à boa-fé, examinando os fins, a estrutura da

28. Id., ibid., p. 129.

29. Id., ibid., p. 129.

30. Id., ibid., p. 129.

31. Id., ibid., p. 129. 
empresa, de cujo seio nasce e se produz através dos órgãos exercentes - um poder discricionário (e normativo) - o direito dos particulares. ${ }^{32}$

6 Outros aspectos pertinentes ao tema e o Direito Agrário Positivo brasileiro

Jean Megret lembra o fato de o Direito Agrário ser uma disciplina bastante jovem, em verdade uma matéria ainda sem seus inícios. Ao lado disso, ela não foi ainda favorecida pela elaboração de um verdadeiro e completo diploma legislativo, dificuldade que se impõe talvez pelo fato de estar o Direito Agrário contemporâneo tão fortemente ligado à economia e às técnicas especiais de produção, de tal forma que o jurista tradicional estaria mal-preparado para alcançar as finalidades maiores da cadeira. ${ }^{33}$

Para Paolo Vitucci, por sua vez, estas dificuldades adviriam de duas razões fundamentais, próprias quando da interpretação de matérias baseadas em leis especiais: em primeiro lugar, trata-se o Direito Agrário de uma disciplina recémintroduzida ou, mais corretamente, de uma disciplina reformada, onde a novidade representa uma dificuldade constante para o intérprete, o qual se acha na obrigação de dever operar sem o subsídio que nas leis já sedimentadas vem oferecido pelo precedente. ${ }^{34}$

Finalizando, uma boa técnica legislativa, acrescentada pelo autor como a segunda razão, poderia aliviar as dificuldades do primeiro impacto hermenêutico; mas os agraristas sabem, e esta é uma característica com a qual convivem também os agraristas brasileiros, quão escassa é a confiança que se pode depositar na qualidade do produto legislativo.

Neste sentido, o art. 103 caput do Estatuto da Terra consubstancia diretriz para a interpretação das normas de Direito Agrário, estatuindo que: "A aplicação da presente Lei deverá objetivar, antes e acima de tudo, a perfeita ordenação do sistema agrário do país, de acordo com os princípios da justiça social, consolidando a liberdade de iniciativa com a valorização do trabalho humano."

32. Id., ibid., p. 130.

33. Megret, Jean, Droit Agraire, 1² ed., Paris, Libraires Techniques, 1976, p. 154.

34. Vitucci, Paolo, ob. cit., p. 8 . 
A integração da norma jurídica agrária permite, através da analogia, preencher lacunas do legislador. Para o entendimento da matéria, há a lição do jurista e professor renomado Rubens Limongi França. ${ }^{35}$

São normas importantes os arts. $92, \S 9^{\circ}$ e 96 , inciso VII e parágrafo único do Estatuto da Terra, art. 13 da Lei n. 4.947/66 e art. 88 do Decreto n. $59.566 / 66$.

O art. 92, § $9^{\circ}$ do Estatuto da Terra estatui: "Para a solução dos casos omissos na presente Lei, prevalecerá o disposto no Código Civil" Tal norma está inserida no Capítulo IV - Do Uso ou da Posse Temporária da Terra, seção I que regula "Das Normas Gerais"

$\mathrm{O}$ art. 96, inciso VII do Estatuto da Terra determina: "- aplicam-se à parceria agrícola, agropecuária, agroindustrial ou extrativa as normas pertinentes ao arrendamento rural, no que couber, bem como as regras do contrato de sociedade, no que não estiver regulado pela presente Lei".

$\mathrm{O}$ art. 13 caput da Lei n. 4.947/66 dispõe: "Os contratos agrários regulam-se pelos princípios gerais que regem os contratos de Direito comum, no que concerne ao acordo de vontade e ao objeto...".

$\mathrm{O}$ art. 88 do Decreto n. 59.566/66 determina: "No que forem omissas as Leis ns. 4.504/64, 4.947/66 e o presente Regulamento, aplicar-se-ão as disposições do Código Civil, no que couber".

O legislador previu que normas pertinentes ao arrendamento poderiam "caber nas avenças de parceria."

Mas devemos reconhecer que o Direito Agrário não desfruta de técnicas particulares acerca da aplicação analógica das regras que o regulam, o que força o intérprete a se utilizar da experiência e de ensinamentos outros, provindos basicamente da elaboração dos civilistas e dos cultores da teoria geral. ${ }^{37}$

Paolo Vitucci, após ressaltar as raízes civilísticas do Direito Agrário e a obviedade da referência ao Código Civil conclui: a especialidade da disciplina volta prepotentemente ao primeiro plano e está sujeita ao interesse convergente do teórico da interpretação, quantas vezes o sistema traçado na lei especial ou nas leis

35. França, Rubens Limongi, Formas e aplicação do direito positivo, $1^{\text {a }}$ ed., São Paulo, RT, 1969 , p. 67 e s. 128

36. Laranjeira, Raymundo, Propedêutica do Direito Agrário, $2^{a}$ ed., São Paulo, LTR, 1981, p.

37. Vitucci, Paolo, ob. cit., p. 5. 
especiais mostrar-se capaz de se auto-integrar, isto é, de preencher as próprias lacunas sem recorrer ao Código Civil ou aos princípios expressos em séde diversa daquele do "microsistema". ${ }^{38}$

São Paulo, novembro de 1995.

38. Id., ibid., p. 13. 